\title{
Integrating Animations in Chinese Character Writing Based on Cognitive Theory of Multimedia Learning to Promote Students' Writing Skills
}

\author{
https://doi.org/10.3991/ijim.v12i7.9671
}

Tan Geok Tin

Sekolah Jenis Kebangsaan Cina Hwa Ming, Malaysia

\author{
Noor Azean Atan $\left.{ }^{\varpi}\right)$, Mohd Nihra Haruzuan Bin Mohamad Said, Mohd Fadzli Ali, \\ Sanitah Mohd, Mohd Zolkifli Abd Hamid \\ Universiti Teknologi Malaysia \& Skudai, Malaysia \\ azean@utm.my
}

\begin{abstract}
The complexity of Chinese character caused students facing learning difficulty in mastering the Chinese character writing skills. This study aimed to investigate the effect and students' perception on the implementation of animation in teaching and learning of Chinese character writing based on Cognitive Theory of Multimedia Learning (AniCC Online Learning) via Frog VLE platform. Meanwhile, the relationship of implementation of AniCC Online Learning and pupil's writing performance was also studied to have further insights into the Chinese character teaching and learning situation. Pre-experimental one group pre-test and post-test design were adopted and thirty three Year 1 students were selected as the respondents in this research which involved four types of instruments. There was a significant different $(p=0.013)$ between the scores of pretest and post-test for students' writing performance after performing paired samples t-test. The study also showed an increase in the means scores of students' writing skills and an increase in the percentage of students' writing skills ranking at rank 4 or above although no significant different $(p=0.180)$ was observed between the pre writing assessment and post writing assessment after Wilcoxon Test was performed. The students overall showed high acceptance towards integration of AniCC Online Learning with overall mean score 0.90 (maximum $=1$ ). In sum, the design of AniCC Online Learning via Frog VLE platform is able to improve writing performance as well as to help students in their writing skills.
\end{abstract}

Keywords-Chinese character writing, animation, Frog VLE, CTML

\section{Introduction}

Writing, as a primary school language basic skill to learn, occupies a very important position in our life. As stated in previous studies, the teaching of writing is the most important prerequisite at the initial stage of Chinese Language learning [1], [2]. The writing ability of Chinese characters influences the lifelong development of the students [1], [3]. According to the Standard Curriculum and Assessment Document (Dokumen 
Standard Kurikulum dan Pentaksiran) of Chinese Language for Chinese primary schools in Malaysia, Year-1 and Year-2 of primary school are a pivotal stage for the students to learn to read and write. Students at this stage have a higher sensitivity of the patterns of the characters [4]. Findings from related researches indicated that, students are required to be proficient in the basic strokes of Chinese characters, strokes order, word structures, sitting posture and in recognizing commonly used radicals, in order to have a good foundation for them to write and eventually to achieve the objectives of writing aesthetics and writing speed [3] - [5]. Mastery of the basic stroke helps students to write Chinese characters with the proper word structure. Thus, the writing efficiency, accuracy, neatness and aesthetics can be increased [6]. Moreover, based on the Standard Curriculum and Assessment Document, upper-grade students in primary schools have to increase their writing speed. Those who fail to write with the correct strokes and strokes order will have difficulties in writing at this stage [4]. This may cause a downfall of learning efficiency among upper-grade students. As a result, the roles of stroke, stroke order, radicals and whole character in handwriting play an important part in Chinese literacy [7].

\subsection{Background of problems}

From a previous study by Law et al. (1998), the researchers found that, stroke production errors brought negative effects on children performance in the Chinese character writing. They proposed that, there are a number of important reasons for teaching the proper writing of the basic stroke forms. Firstly, stroke reversals occur in directions that would lead to poorer and slower handwriting for right-handed scribes. Secondly, since the number of strokes in a character is commonly used as an indexing key in Chinese dictionaries, the inability to identify the correct stroke forms would lead to difficulties in using dictionaries. Thirdly, if children mistake the simple stroke forms to be the only legal stroke forms, then many of the composite or angled strokes would be broken up into disjointed line segments. This would probably increase the difficulties in reproduction memory tasks. Lastly, characters which look similar, but are composed of different basic stroke forms are not considered as the same characters. Stroke production errors may cause difficulties in word recognition [8].

Based on the Standard Curriculum and Assessment Document, the learning goal for Year-1

students is to learn about 500 Chinese characters and write these characters with standard strokes and correct strokes order, as well as developing an interest in writing. Moreover, after six years of a primary school education, students should be able to learn about 2,500 Chinese characters and write these characters with a pencil, a pen or a brush pen [4]. However, according to some of the previous researches, many students fail to master the most basic strokes and the stroke order [5]. Consequently, instead of writing Chinese characters, they are actually "drawing" out the characters. This bad writing habit brings very negative impacts on the writing aesthetic and writing speed. In the study done by Yang Jie in 2015, it was found that, students faced difficulties having a good grasp of writing proper frame structure of the word, with most of the writing not being standardized, while the writing efficiency was lacking [6]. The quality of Chinese 
character writing can be defined according to nine dimensions, namely, interest in writing, sitting posture, pencil holding posture, stroke order, stroke, strength, word structure, character and writing speed[9], [10].

The finding of a previous research showed that, the majority of primary school language teaching and learning in Chinese character writing is still of the traditional teaching methods, where, teachers generally demonstrate writing of the selected Chinese characters on the blackboard, while the students carefully observe it and carry out the writing practice. As most teachers pay more attention to reading literacy, there is short of the attention for the quality of writing [11]. As the teaching strategy is more focused on reading than writing, there is lack of research to study the way to teach students to write in general and to write Chinese characters, in particular [1]. In addition, students are generally inattentive to the importance of writing proper Chinese characters [1]. Furthermore, the requirement for the learners to write with the correct stroke order consumes an excessive classroom time which hinders the teaching and learning of Chinese character writing [12].

Technology integration plays an important role in the teaching and learning of reading literacy, writing and oral communication practices and so on. The quality and efficiency of teaching and learning language is increased with the facilitation of technology [11]. The integration of technology encourages a personalized learning, which allows students to learn at their own pace. Besides, the use of computer technology which combines sound, pictures and animations can increase the learning interest among the students in reading and writing [11]. However, Yu Xi et al. (2013), raised the issue of the impact of the availability of modern technology in character writing pedagogical decisions, with several reviews on the researches being those done from year 2003 until 2008 [12]. Some researches claimed that, with the development of science and technology, as well as the popularity of multimedia such as computers, laptops and mobile devices, the emphasis on writing seems to fade [3], [5], [10]. They claimed that, the prevalence of technology devices does not bring benefits to good writing skills, as the writing practices are taken over by typing practices in the technology integrated classroom [10]. The importance of writing skills seems to be gradually neglected by the society [5].

On the other hand, some scholars have argued the possibility of utilizing modern technology, such as, stroke sequence animation programmes, as computer assisted language learning tools in character learning [12]. Moreover, countless researches have proven that, technology is useful to facilitate and increase the effectiveness of the teaching and learning process. The technology should not be an obstacle in the teaching and learning of Chinese character writing. Nowadays, the Ministry of Educations in all over the world have provided numerous facilities and training to enhance the use of advanced technologies in their respective countries' teaching and learning process. A high budget has been placed to provide the equipment needed by teachers to improve the education system [13]. Psychological theory points out that, people are more efficient in receiving information in a relaxing and harmonious environment. Therefore, a harmonious atmosphere should be created to enable the students to be more effective in learning Chinese characters. In addition, students' personality has to be respected to promote their individual development [14]. As a result, the technology integration for 
instructional purposes becomes a focus which creates learning opportunities that are student-centered, motivating, and participatory [15].

As stated in the Malaysia Education Blueprint (2013 - 2025), among the 11 Shifts to Transform the Education System, the Shift 7 is intended to leverage ICT to scale up a quality learning across Malaysia [16], [17]. In accordance with this shift, a number of measures have been implemented by the Ministry of Education (MOE), including the provision of an internet access and a virtual learning environment (Frog VLE) via 1BestariNet for all 10,000 schools, augment online content to share best teaching practices starting with a video library of top-performing teachers delivering lessons in Science, Mathematics, Malay Language and English language and maximizing the use of ICT for a distant and self-paced learning to expand students' access to a high-quality teaching, regardless of the location or the skill level [16].

Frog VLE, is the nationwide initiative taken by the Ministry of Education Malaysia [18]. Playing active roles as educators, the modernization of education should be vigorously developed, giving a meticulous attention to the application of modern technology in teaching. The information-based teaching system is characterized by the involvement of modern educational media. The development of information technology can indeed, to a certain extent, facilitate the teaching of writing; teachers are no longer only writing on the blackboard, but also using the multimedia display to provide examples to improve the efficiency of teaching [18]. However, the study of LuXiao (2016) pointed out that, only about $10 \%$ of the teachers in the language classroom can use information technology to participate in writing teaching, to show students about writing Chinese characters, to do presentation and to explain writing processes [1]. Nonetheless, the development of modern information technology should serve all aspects of education to increase the efficiency in teaching and learning.

\subsection{Theoretical Framework}

You may also simply delete all the text in this document, paste yours and format it with the styles. This study draws its theoretical guidelines from the Cognitive Theory of Multimedia Learning (CTML) as shown in Figure 1 [19]. The Cognitive Theory of Multimedia Learning (CTML) argues that, multimedia supports the way that the human brain learns [20].

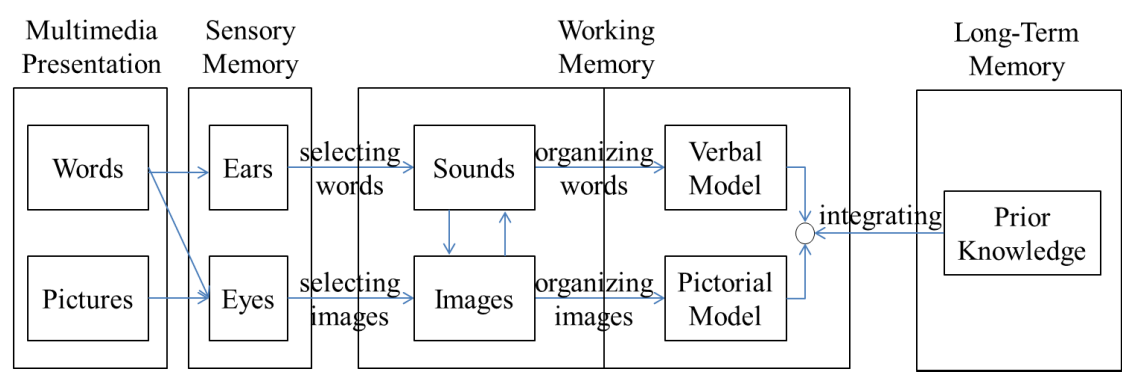

Fig. 1. Conceptual Framework of the Study 
On the other hand, Figure 2 shows the conceptual framework of the study.

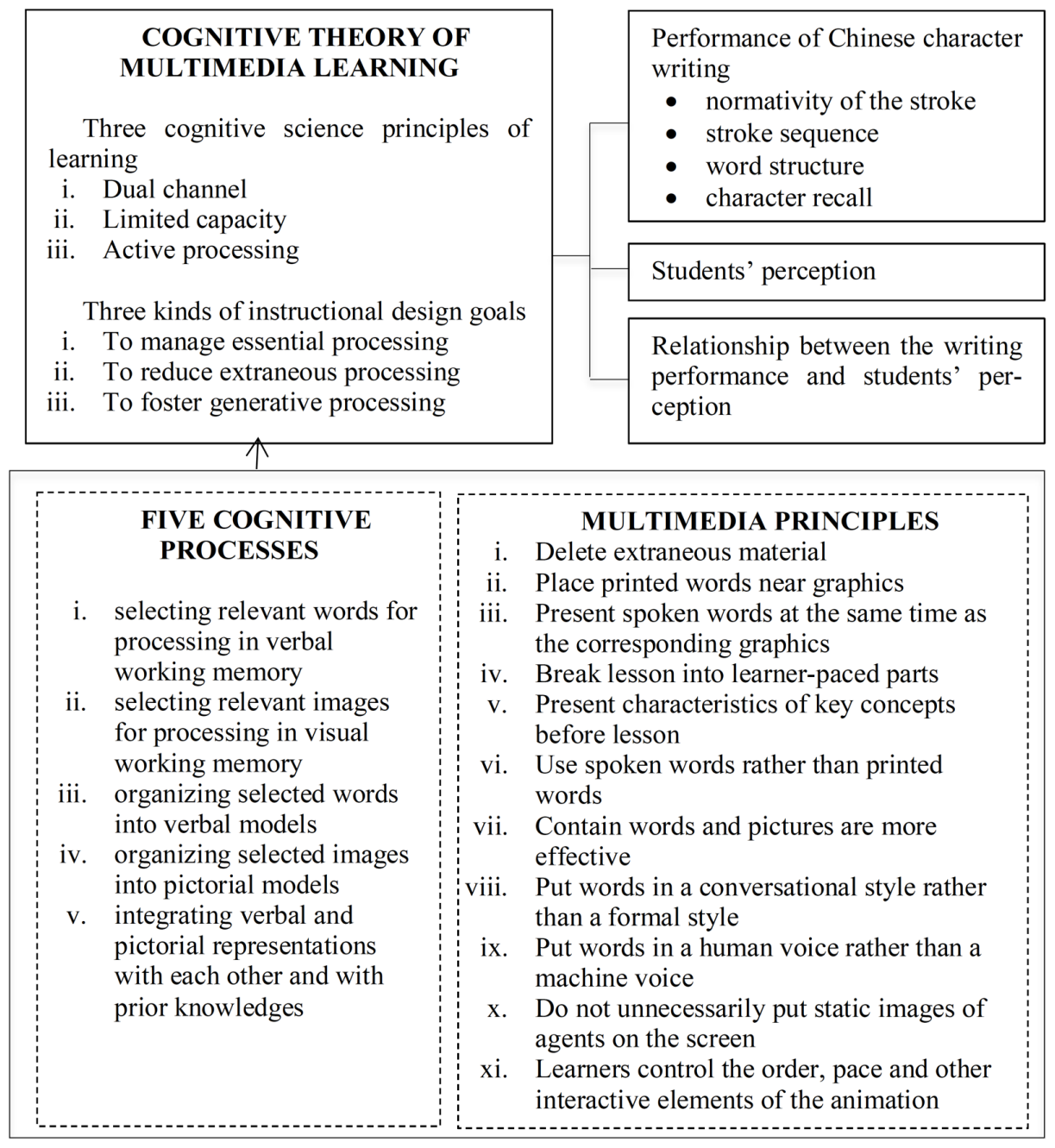

Fig. 2. Conceptual Framework of the Study

This study investigated the current situation of teaching and learning of Chinese character writing. The Animation in Chinese character writing based on Cognitive Theory of Multimedia Learning (AniCC) Online Learning platform was developed in order to study the effectiveness in teaching and learning of Chinese character writing among Year-1 students. Besides, the students' perception towards AniCC Online Learning was also studied.

Finally, this study also examined the relationship between writing performance in Year-1 Chinese Language classrooms and students' perception in the implementation AniCC Online Learning. 


\subsection{Research Objectives}

The objectives of this research were:

i) To study the effect of the implementation of AniCC Online Learning in Year-1 Chinese Language classrooms on students':

- performance of Chinese character writing in the aspects of normativity of the stroke, stroke sequence and word structure

- writing skills

ii) To investigate students' perception towards AniCC Online Learning in Year-1 Chinese Language classrooms.

iii) To examine the relationships between students' writing performance in Year-1 Chinese Language classrooms and their perception in the implementation AniCC Online Learning

\section{Methodology}

A quantitative research approach was used to evaluate the test and survey data, based on the research questions of this study. A Pre-Experimental One Group Pre-test and Post-test Design was adopted in this study, which involved a total of 33 Year-1 students. These respondents were required to take a pre-test to determine the baseline scores and a post-test to study the effects of animation based on CTML in teaching and learning of Chinese character writing. A pilot test was carried out to obtain the reliability of the instruments. The Cronbach Alpha values for the pre-test and pre writing assessment, as well as the perception instruments, ranged between 0.738 and 0.800 , which indicated that, the reliability of the pre-test and pre writing assessment instrument was acceptable and the reliability of the perception instrument was good. The study involved four types of instruments, namely, pre-test and pre writing skills assessments, post-test and post writing skills assessments, rubric of evaluation of Chinese character and students' perceptions questionnaire towards the integration of AniCC Online Learning in Chinese classroom. The pre-test and post-test were divided to 3 constructs. Construct A contained questions about stroke order, construct B contained questions about stroke number, while construct $C$ contained questions about word structure. Subsequently, the writing skills were evaluated based on six writing criteria, namely, normative and correct, stroke order, letter formation, letter sizing, placement and writing speed. Besides, a 2-Likert scale survey questionnaire of students' perception towards the integration of animation using Frog VLE platform based on CTML, was also distributed to the each of the students. It comprised 2 constructs, namely Construct 1: Integration of AniCC Online Learning, and Construct 2: Writing experience. The quantitative data collected in this study were analyzed descriptively and inferentially, based on the research, using the Statistical Package for the Social Sciences (SPSS) software. 


\section{Data Analysis And Results}

Paired samples t-test was conducted for the data obtained from pre-test and post-test to compare the means scores in determining students' writing performance, which results are shown in Table 1 . As can be seen, there was a statistically significant difference in the mean scores of the students' writing performance, between the pre-test and post-test $(\mathrm{t}=-2.623, \mathrm{p}=.013, \mathrm{df}=32, \alpha<.05)$. This indicated that, the implementation of AniCC Online Learning in the Chinese Language classroom caused a significantly positive effect in teaching and learning of Chinese character writing.

The mean scores for students' writing skills are shown in Table 2. The maximum score for each writing criteria was 3 according to the rubric. The results indicated that, the students recorded the lowest mean scores for stroke order and letter formation, both at 1.90. In general, an increase was observed in the mean scores of the students' writing skills, from 2.02 in the pre writing assessment to 2.09 in the post writing assessment.

Table 3 showed the percentage of students, based on the ranking of their writing skills in both the pre writing assessment and post writing assessment. The majority of the students recorded the above-average rank for both pre writing assessment and post writing assessment. An increase in the percentage of students in the above-average rank was recorded in the post writing assessment.

Table 1. Paired Samples T-Test

\begin{tabular}{|c|c|c|c|}
\hline Test & $\mathbf{t}$ & Df & Sig. (2-tailed) \\
\hline Pair Pre-test - Post-test & -2.623 & 32 & .013 \\
\hline
\end{tabular}

Table 2. Mean Scores for Students' Writing Skills

\begin{tabular}{|l|l|l|c|}
\hline \multicolumn{1}{|c|}{ Criteria } & Pre & Post & Mean \\
\hline Normativity & 2.03 & 2.03 & 2.03 \\
\hline Order & 1.88 & 1.91 & 1.90 \\
\hline Letter Formation & 1.76 & 2.03 & 1.90 \\
\hline Letter Sizing & 2.18 & 2.21 & 2.20 \\
\hline Placement & 1.94 & 2.24 & 2.09 \\
\hline Writing Speed & 2.30 & 2.12 & 2.21 \\
\hline Mean & 2.02 & 2.09 & 2.06 \\
\hline
\end{tabular}

Table 3. Percentage of Students' Writing Skills Ranking

\begin{tabular}{|c|c|c|}
\hline Rank & $\begin{array}{c}\text { Pre Writing Skills } \\
\text { (\% of Students) }\end{array}$ & $\begin{array}{c}\text { Post Writing Skills } \\
\text { (\% of Students) }\end{array}$ \\
\hline $\mathbf{1}$ & 0 & 0 \\
\hline $\mathbf{2}$ & 3.0 & 3.0 \\
\hline $\mathbf{3}$ & 30.3 & 21.2 \\
\hline $\mathbf{4}$ & 60.6 & 69.7 \\
\hline $\mathbf{5}$ & 6.1 & 6.1 \\
\hline Total & 100.0 & 100.0 \\
\hline
\end{tabular}

Rank: 1 = Very Poor; 2 = Below Average; $3=$ Average $; 4=$ Above Average $; 5=$ Excellent 
In addition, the rankings of the students' writing skills were further studied to compare the difference between the pre writing assessment and the post writing assessment, using a non-parametric Wilcoxon test, which results are as in Table 4. The test was performed to compare the rankings of writing skills for the pre writing assessment and the post writing assessment, because the mean scores obtained for the students' writing skills did not approximate a normal distribution. The results of the test showed that, there was no significant difference in the rankings of the writing skills for the pre writing assessment and post writing assessment among the students $(Z=-1.342, p=.180)$. The average rank at 3.00 indicated that, most of the students' writing skills were at the average rank. This suggested that, the AniCC Online Learning in Chinese Language Classroom had no significant impact on the writing skills among the students, statistically. However, an increase in the means scores between the pre writing assessment and the post writing assessment and an increase in the percentage for the students who obtained rank 4 or above were also recorded in this study.

Table 5 shows the percentage of respondents who agreed and disagreed to each question in the students' perception questionnaire on the use of AniCC Online Learning in learning activities for Chinese Language classroom. The questionnaire was divided to two constructs, the first examining the students' perception in the aspect of the AniCC Online Learning platform, while the second focusing on the perception of writing experience after the implementation of AniCC Online Learning.

Table 4. Analysis of Wilcoxon Test Comparing the Writing Skill Rank for Pre-test and Posttest

\begin{tabular}{|l|c|c|c|c|c|}
\hline Pre-test and Post-test & $\mathbf{n}$ & Mean Ranks & Sum of Ranks & $\mathbf{z}$ & $\mathbf{p}$ \\
\hline Negative Ranks & $1^{\mathrm{a}}$ & 3.00 & 3.00 & $-1.342^{\mathrm{d}}$ & .180 \\
\hline Positive Ranks & $4^{\mathrm{b}}$ & 3.00 & 12.00 & & \\
\hline Ties & $28^{\mathrm{c}}$ & & & & \\
\hline Total & 33 & & & & \\
\hline
\end{tabular}

*a. Post_WS_Rank $<$ Pre_WS_Rank

*b. Post WS Rank > Pre WS Rank

*c. Post_WS_Rank $=$ Pre_WS_Rank

$*$ d. Based on negative ranks

Table 5. The Percentage of Students' Perception Regarding AniCC Online Learning Platform

\begin{tabular}{|c|l|c|c|}
\hline No. & \multicolumn{1}{|c|}{ Items } & Agree(\%) & Disagree (\%) \\
\hline $\mathbf{1}$ & It is easy to learn to use this AniCC Online Learning. & 93.9 & 6.1 \\
\hline $\mathbf{2}$ & The materials used in the learning site are satisfying. & 90.9 & 9.1 \\
\hline $\mathbf{3}$ & The AniCC Online Learning provides valuable learning experiences. & 93.9 & 6.1 \\
\hline
\end{tabular}

Based on Table 5, the overall percentages of the questions of students' perception on AniCC Online Learning platform were observed. It can be summarized, as a whole, most of the students agreed to the questionnaires, with the percentage greater than $90 \%$ for each question. Additionally, another set of questions regarding students' perception towards writing experience after using AniCC Online Learning were also given to the 
students. The percentage of students for each question is shown in Table 6 below. Based on Table 6, the students who agreed that, using AniCC Online Learning in Chinese Language classroom aroused their interest in learning Chinese character writing, recorded the highest percentage. However, those who agreed that, the AniCC Online Learning platform helped them to learn the word structure, those recorded the lowest percentage.

In addition, a survey was carried out to study the acceptance of each learning activity among the students. Table 7 below shows the descriptive data for the students' perception in each learning activity. Based on the results obtained, the drag and drop game had the highest mean score among the six learning activities, indicating that, it was the most preferred learning activity.

Table 6. The Percentage of Students' Perception regarding Chinese Character Writing Experience

\begin{tabular}{|c|l|c|c|}
\hline No. & \multicolumn{1}{|c|}{ Items } & \multicolumn{1}{|c|}{ Agree (\%) } & Disagree (\%) \\
\hline $\mathbf{1}$ & The AniCC Online Learning aroused my interest in Chinese characters. & 97.0 & 3.0 \\
\hline $\mathbf{2}$ & $\begin{array}{l}\text { The AniCC Online Learning increased students' motivation in learning } \\
\text { the characters. }\end{array}$ & 81.8 & 18.2 \\
\hline $\mathbf{3}$ & The AniCC Online Learning made Chinese characters easier to learn. & 81.8 & 18.2 \\
\hline $\mathbf{4}$ & $\begin{array}{l}\text { The AniCC Online Learning helped me a lot in understanding the Chi- } \\
\text { nese characters. }\end{array}$ & 81.8 & 18.2 \\
\hline $\mathbf{5}$ & $\begin{array}{l}\text { The AniCC Online Learning helped me a lot in remembering the Chi- } \\
\text { nese characters. }\end{array}$ & 87.9 & 12.1 \\
\hline $\mathbf{6}$ & $\begin{array}{l}\text { The AniCC Online Learning helped me to learn the pronunciation of } \\
\text { the word. }\end{array}$ & 93.9 & 6.1 \\
\hline $\mathbf{7}$ & The AniCC Online Learning helped me to learn the stroke order. & 84.8 & 15.2 \\
\hline $\mathbf{8}$ & The AniCC Online Learning helped me to learn the proper stroke. & 90.9 & 9.1 \\
\hline $\mathbf{9}$ & The AniCC Online Learning helped me to learn the word structure. & 75.8 & 24.2 \\
\hline $\mathbf{1 0}$ & The AniCC Online Learning helped me to learn the radical. & 87.9 & 12.1 \\
\hline $\mathbf{1 1}$ & The AniCC Online Learning increased my writing speed. & 78.8 & 21.2 \\
\hline $\mathbf{1 2}$ & The AniCC Online Learning helped me to learn the word formation. & 84.8 & 15.2 \\
\hline
\end{tabular}

Table 7. Mean Score of the Learning Activities

\begin{tabular}{|l|c|c|c|c|c|}
\hline & N & Minimum & Maximum & Mean & Std. Deviation \\
\hline Audio & 33 & 1 & 5 & 4.09 & 1.208 \\
\hline Graphic & 33 & 1 & 5 & 3.73 & 1.126 \\
\hline Animation & 33 & 2 & 5 & 4.09 & .980 \\
\hline Game & 33 & 1 & 5 & 4.48 & .972 \\
\hline Writing & 33 & 1 & 5 & 4.03 & 1.185 \\
\hline Vote & 33 & 1 & 5 & 3.85 & 1.228 \\
\hline
\end{tabular}


A correlation statistical procedure was conducted to examine the relationship between students' perception of AniCC Online Learning and their writing performance. Table 8 shows the results obtained after conducting a Spearman's rho analysis. Spearman's correlation coefficient is a non-parametric measure, comparable to Pearson's product moment correlation coefficient. Spearman's coefficient looks at orders and assesses the association between two variables using ranks, rather than actual values. This coefficient is considered more appropriate than Pearson's, because the mean scores of perception towards AniCC Online Learning in Chinese Language classroom showed deviations from normality. The results obtained showed that, there is no correlation between students' perception on AniCC Online Learning and their writing performance $(\mathrm{p}=0.994)$.

Table 8. Relationship Between Students' Perception on AniCC Online Learning and Their Writing Performance

\begin{tabular}{|c|c|c|c|c|}
\hline \multicolumn{2}{|c|}{} & Mean Perception & Post-test \\
\hline \multirow{4}{*}{ Spearman's rho } & \multirow{3}{*}{ Mean Perception } & Correlation Coefficient & 1.000 & .001 \\
\cline { 3 - 5 } & & Sig. (2-tailed) &. & .994 \\
\cline { 3 - 5 } & \multirow{3}{*}{ Post-test } & N & 33 & 33 \\
\cline { 3 - 5 } & & Correlation Coefficient & .001 & 1.000 \\
\cline { 3 - 5 } & & Sig. (2-tailed) & .994 &. \\
\cline { 3 - 5 } & & $\mathrm{N}$ & 33 & 33 \\
\hline
\end{tabular}

$a>0.05$

\section{Discussion}

For the purpose of investigating the Students' Writing Performance, paired samples $\mathrm{t}$-tests were conducted to compare the mean scores of their writing performance and writing skills, using a pre-test and post-test respectively. Results of the tests showed statistically significant differences $(\mathrm{p}=.015)$ between the pre-test and post-test at 0.05 level (Table 1). In the post-test, an increase in the mean scores of students' writing performance was observed. The AniCC Online Learning site was proven to have a positive effect on the student's writing performance, based on the scores they obtained in the pre-test and post-test. These results are consistent with the findings in a research done by Yue $e t$ al. in 2013 which proposed that, the application of multimedia learning principles to the development of instructional animations could contribute to learners' overall comprehension of the learning material [21].

On the other hand, no significant difference was observed in the rank of the students' pre writing skills and post writing skills, although the mean scores increased by 0.7 mark from 2.02 to 2.09 , by comparing the pre writing assessment and the post writing assessment in this study, as shown in Table 2. Besides, an increase in the percentage of students who obtained rank 4 or above for the post writing assessment was also observed, as shown in Table 3. These results were well in agreement to the findings in Bull's research, which proposed that students are engaged and motivated to learn when 
the teachers create functional digital learning materials for their classrooms, thus, enhancing learning [22]. This suggests that, multimedia material is useful when it provides a meaningful context and a memory aid to the learner. The results are consistent with Mayer's model, based on the Cognitive Theory of Multimedia Learning (CTML), where an attention must be paid for learning to take place. According to Mayer, multimedia contexts facilitate the provision of meaningful input, foster interaction, and enhance learning among the students [23].

The survey of students' perception towards the implementation of AniCC Online Learning in Year-1 Chinese language classroom was divided to two main constructs, the first focusing on AniCC Online Learning platform, while the second focusing on students' writing experience. Table 5 shows the percentage of students' perception towards AniCC Online Learning in Year-1 platform. In general, students showed positive responses for the perception towards AniCC Online Learning platform with the percentage greater than $90 \%$ for each question. The results are corresponding to teacher's perception after using AniCC Online Learning in the Year-1 Chinese Language classroom. The teacher stated thus:

Teacher: "The learning content in the AniCC Online Learning platform is useful. It helps the students to be engaged in teaching and learning activities and consequently to improve their writing ability."

In terms of the students' perception of writing experience, the highest percentage of them agreed that, AniCC Online Learning aroused their interest in learning Chinese characters. The results are consistent with the teacher's feedback as follows:

Teacher: "The students are very interested in the learning activities using AniCC Online Learning. They show a higher concentration in the classroom using the online learning site. In addition, the AniCC Online Learning also serves as a beneficial learning for the students' self-learning at home."

These results are in agreement with the findings in the research by Bauman in 2016 which drew to a conclusion that, students were comfortable with the use of technology [24]. Similar research also showed that the students are interested in VLE and the involvement of the student in learning process via VLE platform was high [25]. Moreover, the positive responses reported by the students regarding the acceptability and usability of online learning are also corresponded to the results reported in a research by Asiry [26]. In addition, according to Gurer (2016), the pre-service teachers' level of perception on using technology for education purposes is at high level [27]. The findings in the researches are in line with the perception of technology integration in the classroom in the current study.

There were six activities provided in AniCC Online Learning, namely, listening to human voice recording audio, learning Chinese character using resemble graphics, learning Chinese character using animation, drag and drop game, online Chinese character writing and online voting. From the analysis showed in Table 7, the drag and drop game recorded the highest preference among the students. These results are consistent with the interactivity multimedia learning principle which stated that, an interactive environment helps learners engage in the material and generates coherent mental models to facilitate an understanding [21]. In line with the research by Nicholas (2015), the 
findings also indicated that, interactivity of digital learning object enhances and amplifies the cognitive processes of learners which is aligned with the affective characteristics of learners [28].

Table 8 shows the relationship between students' perception of AniCC Online Learning and writing performance. As can be seen, no significant relationship is observed between the two variables. This is in contrast with the findings in Guo's research in 2017 which stated that, students' perceptions of the learning environment were found to have a direct effect on learning outcomes [29]. In addition, a research by Chang and $\mathrm{Yu}$ in 2015 also drew to a conclusion that, learners' perceptions of an innovative environment had high positive correlations with the creative performance [30]. However, the results in this study showed the contrary situation. This might be due to the short research duration of only four weeks, rendering it insufficient to have significant changes in writing skills although the students generally had positive responses towards the integrated AniCC Online Learning in their Chinese Language classroom.

As stated in the review done by Rahman et al., most of the studies produced positive results that can enhance the virtual world's reputation as an effective learning platform today [31]. The findings of this study also provide some positive implications for the teaching and learning of Chinese characters in Year-1 classroom. The design of AniCC Online Learning platform, based on Cognitive Theory of Multimedia Learning, is able to improve writing performance as well as to help students in their writing skills. In addition, this study also has a positive implication on the development of the implementation of Frog VLE in the current teaching and learning of Year-1 Chinese Language, because the newly designed learning activities in the Frog VLE platform are based on the syllabus of Standard Curriculum and Assessment Document. Moreover, the AniCC Online Learning is also shared publically and it can be reviewed by all concerned educators. This research also aims to help instructional and multimedia designers understand the Cognitive Theory of Multimedia Learning and the different principles to enhance the teaching and learning processes. The present study highlights the need for instructional researches on the way Chinese characters can be more effectively taught to the Year-1 students. In accordance with the study by Bull (2013), there are several technical limitations, such as, time constraints, copyright material, technical support, and access to a server that could limit how effective multimedia software and applications or online learning could be in creating instructional multimedia pieces [22].

\section{Conclusion}

In summary, as stated in Yue et al. (2013), the application of multimedia learning principles to the development of instructional animations is contributing to learners' overall comprehension of the learning material [21]. In this research, AniCC Online Learning was implemented within 4 weeks of actual study among Year-1 students. The design of the learning activities via Frog VLE platform was based on the Cognitive Theory of Multimedia Learning (CTML). The overall findings of the study, involving 
a total of 33 students in Year-1 from the same class going through the process of teaching and learning of Chinese character writing, showed that, all of them had improved, in terms of the writing performances with positive responses on their perception towards the integration of AniCC Online Learning in the classroom. Thus, AniCC Online Learning is recommended to be used in teaching and learning of Chinese character writing.

\section{Acknowledgment}

The authors would like to deliver the greatest appreciation to Ministry of Higher Education and Universiti Teknologi Malaysia for supporting this study. Also, the authors would like to acknowledge that this work is supported by the Fundamental Research Grant Scheme with Reference Code FRGS/2/2013/SSI09/UTM/03/1

\section{$7 \quad$ References}

[1] LuXiao. (2016). Problems and Countermeasures of Writing Teaching in Primary School. Ludong University.

[2] Jing Jing, L. (2016). The Investigation and Analysis of Chienese Literacy and Hand-writing Teaching Situatin In The Low Grades of Yanji Jinxue Primary School. Uni-versity in Yanbian Korean Autonomous Prefecture, China.

[3] MingYu, Y. (2015). Chinese Characters Under the Crisis of Primary School Chinese Teaching Research. Bohai University. Retrieved from http://cdmd.cnki.com.cn/Article/CDMD10167-1015322255.htm

[4] Bahagian Pembangunan Kurikulum. (2015). Kurikulum Standard Sekolah Rendah Bahasa Cina (SJK).

[5] BoHeng, F. (2015). Chinese Writing Teaching Strategy in Primary School. Bohai Uni-versity.

[6] Jie, Y. (2015). Effectiveness of teaching in primary grades in writing. Guizhou Normal University.

[7] Guan, C. Q., Liu, Y., Chan, D. H. L., Ye, F. and Perfetti, C. A. (2011). Writing strength-ens orthography and alphabetic-coding strengthens phonology in learning to read Chinese. Journal of Educational Psychology, 103(3), 509-522. https://doi.org/10.1037/a0023730

[8] Law, N., Ki, W. W., Chung, A. L. S., Ko, P. Y., and Lam, H. C. (1998). Children's stroke sequence errors in writing Chinese characters. Reading and Writing: An Inter-disciplinary Journal 10:, (10), 267-292. https://doi.org/10.1023/A:1008091730338

[9] Qun, G. (2013). DefineWriting Disabilities and Evaluate Writing Quality. Chinese Journal of Special Education (Monthly), 2, 51-56.

[10] Hao, L. (2015). Lower primary students writing literacy situation and recomendations for improvement - A Case Study in Changchun N Primary. Northeast Normal Univer-sity.

[11] Ai Xiang, Y. (2012). Thinking and countermeasures of teaching reform on primary school literacy and writing teaching. Hunan Normal University.

[12] Xu, Y., Chang, L. Y., Zhang, J., and Perfetti, C. A. (2013). Reading, writing, and anima-tion in character learning in chinese as a foreign language. Foreign Language Annals, 46(3), 423 444. https://doi.org/10.1111/flan.12040 
[13] Ghavifekr, S., and Athirah, W. R. (2015). Teaching and Learning with Technology: Effectiveness of ICT Integration in Schools, 1(2), 175-191.

[14] JunXia, H. (2015). Dialect District of western Inner Mongolia the elementary school low section literacy teaching research. China Academic Journal Electronic Publishing House. Inner Mongolia Normal University. Retrieved from http://cdmd.cnki.com.cn/Article/CDMD-10135-1015432144.htm

[15] Hakverdi-Can, M., and Sönmez, D. (2012). Learning how to design a technology sup-ported inquiry-based learning environment. Science Education International, 23(4), 338-352.

[16] Preliminary Report Malaysia Education Blueprint 2013-2025. (2013). Malaysia Edu-cation Blueprint, 35. Retrieved from http://www.moe.gov.my/userfiles/file/PPP/PreliminaryBlueprint-Eng.pdf

[17] Jamil, H. (2014). Teacher is Matter for Education Quality : A Transformation of Poli-cy for Enhancing the Teaching Profession in Malaysia. Jornal of International Cooper-ation in Education, 16(2), 181-196.

[18] Hiong, S. N., and Agatha, F. U. (2015). A Pilot Study on Factors Affecting the Use of Frog Virtual Learning Environment. Jurnal Penyelidikan IPG KBL Jilid, 12, 1-17.

[19] Mayer, R. E. (2014). Cognitive theory of multimedia learning. The Cambridge Hand-book of Multimedia Learning, Second Edition. https://doi.org/10.1017/CBO9781139547369.005

[20] Sorden, S. D. (2012). The cognitive theory of multimedia learning. Handbook of Educational Theories, 1-31. https://doi.org/10.3102/0091732X09358129

[21] Yue, C., Kim, J., Ogawa, R., Stark, E., and Kim, S. (2013). Applying the cognitive theo-ry of multimedia learning: An analysis of medical animations. Medical Education, 47(4), 375387. https://doi.org/10.1111/medu. 12090

[22] Bull, P. H. (2013). Cognitive Constructivist Theory of Multimedia: Designing Teach-erMade Interactive Digital. Creative Education, 4(9), 614-619. https://doi.org/10.4236/ce. $\underline{2013.49088}$

[23] Mayer, R. E. (2009). Research-Based Principles for Designing Multimedia Instruction Overview of Multimedia Instruction. (V. A. Benassi, Ed.).

[24] Bauman, A. (2016). Students' perceptions of the use of technology in cross-cultural communication. Higher Education, Skills and Work-Based Learning, 6(2), 193-207. https://doi.org/10.1108/HESWBL-06-2015-0034

[25] Kiat, L. B., Ali, M. B., Halim, N. D. A., \& Ibrahim, H. B. (2016). Augmented Reality, Virtual Learning Environment and Mobile Learning in education: A comparison. 2016 IEEE Conference on E-Learning, e-Management and e-Services (IC3e), 23-28. https://doi.org/10.1109/IC3e.2016.8009034

[26] Asiry, M. A. (2017). Dental students' perceptions of an online learning. The Saudi Dental Journal, 29(4), 167-170. https://doi.org/10.1016/j.sdentj.2017.03.005

[27] Gurer, M. D. (2016). Preservice Teachers' Perception of Technology Use in Classroom, (2015), 2854-2859.

[28] Nicholas, A. F. (2015). Digital Learning Objects: Design For Learning. University of Canterbury.

[29] Guo, J., Yang, L., and Shi, Q. (2017). Effects of perceptions of the learning environ-ment and approaches to learning on Chinese undergraduates' learning. Studies in Edu-cational Evaluation, 55(422), 125-134. https://doi.org/10.1016/j.stueduc.2017.09.002

[30] Chang, Y. S., and Yu, K. C. (2015). The relationship between perceptions of an inno-vative environment and creative performance in an online synchronous environment. Computers in Human Behavior, 49, 38-43. https://doi.org/10.1016/j.chb.2015.02.040 
Paper-Integrating Animations in Chinese Character Writing Based on Cognitive Theory of Multimedia...

[31] Rahman, M. H. A., Yahaya, N., \& Halim, N. D. A. (2014). Virtual World for Collabora-tive Learning: A Review. 2014 International Conference on Teaching and Learning in Computing and Engineering, 52-57. https://doi.org/10.1109/LaTiCE.2014.18

\section{Authors}

Noor Azean Atan, Mohd Nihra Haruzuan, Mohd Fadzli Ali, Sanitah Mohd Yusof and Mohd Zolkifli Abd Hamid are senior lecturer at Faculty of Education, Universiti Teknologi Malaysia, 81310 UTM Skudai, Johor, MALAYSIA.

Article submitted 08 October 2018. Resubmitted 28 October 2018. Final acceptance 08 November 2018. final version published as submitted by the authors. 